\title{
Decreases in pediatric fractures during the COVID-19 pandemic — a nationwide epidemiological cohort study
}

\author{
Galia Zacay $^{1,2} \cdot$ Dalit Modan-Moses ${ }^{1,2,3} \cdot$ Liana Tripto-Shkolnik ${ }^{1,2,4} \cdot$ Yael Levy-Shraga ${ }^{1,2,3}$
}

Received: 30 July 2021 / Revised: 12 November 2021 / Accepted: 15 November 2021 / Published online: 7 January 2022

(c) The Author(s), under exclusive licence to Springer-Verlag GmbH Germany, part of Springer Nature 2021

\begin{abstract}
The COVID-19 pandemic led to fundamental changes in daily routines of children. Our aim was to evaluate the incidence and characteristics of fractures among Israeli children during 2020 compared with 2015-2019. Demographic, clinical data, and incidence rates of fractures in individuals aged $<18$ years were derived from the electronic database of Meuhedet Health Services, which provides healthcare services to 1.2 million people in Israel. We further subdivided the year to five periods according to government regulations of lockdown and isolation at each period. Fracture sites were determined according to ICD9 definitions. During 2020, 10,701 fractures occurred compared with 12,574 \pm 599 fractures per year during 2015-2019 ( $p$-value $<0.001)$. Fracture rates were lower during all periods in 2020. The largest decline was observed during the first lockdown for both boys (56\% decline, 95\% confidence interval [CI] 52-60\%) and girls (47\% decline CI 41-53\%). While the fracture rate declined for most age groups, the largest decline was recorded for the age group 11-14 years, with significant reduction rates of 66\% (CI 59-71\%) for boys and 65\% (CI 54-73\%) for girls. The most prominent declines were of fractures of the hand bones of both boys and girls ( $64 \%$ and $59 \%$, respectively).

Conclusions: Our data showed a significant decrease in fracture rate in 2020 compared to the previous 5 years, as well as differences between periods within that year.

\section{What is New:}

-The COVID-19 pandemic led to fundamental change in daily routines of children with significant decrease in school attendance and sport activities.

- Consequent to these public health measures, the incidence rate of pediatric fractures decreased significantly.

What is New:

-This study demonstrates declines in fracture rates during lockdown periods, with only partial reversing of the trends between the lockdown periods.

- The most pronounced decline was observed during the first lockdown period.

-The decline was most prominent in children aged 11-14 years; there was no significant change in fracture incidence of children aged $<3$ years.
\end{abstract}

Keywords Fracture $\cdot$ Children $\cdot$ Epidemiology $\cdot$ COVID-19

\section{Introduction}

Yael Levy-Shraga

yael.levy.shraga@gmail.com

1 Meuhedet Health Services, Tel Aviv, Israel

2 Sackler School of Medicine, University of Tel Aviv, Tel Aviv, Israel

3 Pediatric Endocrinology and Diabetes Unit, The Edmond and Lily Safra Children's Hospital, Chaim Sheba Medical Center, Tel-Hashomer, Israel

4 Division of Endocrinology, Diabetes and Metabolism, Sheba Medical Center, Tel-Hashomer, Israel
Coronavirus disease 2019 (COVID-19) was declared by the World Health Organization a public health emergency on January 20, 2020, and a pandemic on March 11, 2020 [1]. The high morbidity and mortality of COVID-19 have prompted drastic public health measures by governmental organizations around the world, including recommendations for significant social distancing, self-isolations, and lockdowns. These measures led to fundamental changes in daily routines of children. School attendance, travel, outdoor activities, and organized sports decreased substantially. 
Fractures are a common traumatic injury of children; approximately one-third of all children sustain at least one fracture before age 17 years [2]. Pediatric fractures are more common in boys, mainly during adolescence [3], and are related to participating in sport activities [4].

Several studies evaluated pediatric injuries, and specifically fractures, during the COVID-19 pandemic [5-12]. Most of them presented data from a single trauma center and focused on the short period in the early stage of the COVID19 pandemic, between March and May 2020 (Table 1).

Our aim was to evaluate the incidence and characteristics of fractures among Israeli children during the entire year of 2020 compared to the previous 5 years, 2015-2019. We subdivided the year 2020 to five periods according to government regulations of lockdown and isolation, to compare differences in fractures between the periods. These data may help outline recommendations for pediatric orthopedic trauma centers in subsequent epidemics, aimed to redirect valuable medical personnel resources.

\section{Methods}

\section{Data extraction and the study population}

We searched the database of Meuhedet Health Services for fractures recorded during 2015-2020 in the pediatric population, aged $<18$ years old. Meuhedet is a health maintenance organization that provides complete healthcare services to 1.2 million people distributed throughout the country. A comprehensive database contains information from laboratory tests, imaging studies, office and emergency room visits, prescriptions, and hospital discharge records. We obtained demographic information, namely age and gender, and the dates and site of fractures.

\section{Diagnosis of fractures}

Fractures were classified according to the International Classification of Disease (ICD)-9 codes 800-829, as recorded in ambulatory and hospital emergency rooms visits. To differentiate between a single fracture event that was recorded in repetitive visits, and two distinct fracture events, we defined a period within all fracture diagnoses related to the same fracture. For this preliminary process, we extracted all fracture diagnoses of the first 200 children who experienced a fracture during 2019. We then manually reviewed electronic medical records of the patients and used the results as a guideline. A cutoff of 90 days from the previous fracture diagnosis was used to define a new fracture, with sensitivity to identify two distinct fracture events of $88 \%$ and specificity to identify a single fracture event of $95 \%$.

\section{COVID-19 lockdowns and analysis periods}

The year 2020 included two lockdown periods in Israel, during which children did not attend schools and studied at home, using remote learning aids. We analyzed separately each of the following periods:

Period 1 - from 1.1.20 until 13.3.20 (72 days), before the first lockdown.

Period 2 - from 14.3.20 until 2.5.20 (50 days), the first lockdown. Children of all ages did not attend schools and public playgrounds were closed.

Period 3 - from 3.5.20 until 17.9.20 (138 days) schools were open partially and intermittently.

Period 4 - from 18.9.20 until 16.10.20 (29 days), the second lockdown. Children did not attend schools; the playgrounds were open.

Period 5 - from 17.10.20 until 27.12.20 (72 days), schools were open partially and intermittently. Children up to age 7 years (second grade) attended schools and kindergartens, children aged 8-12 (3rd to 6th grades) and 16-17 (11th and 12th grades) attended schools 2-3 days per week, while children aged 13-16 (7th to 10th grades) studied at home throughout this period.

On 28.12.20, a third lockdown began. Hence, the period of 28-31.12.20 was not included in the analysis.

We compared the incidences of childhood fractures during the above five periods with the mean incidences of fractures during parallel periods in the years 2015-2019.

\section{Statistical analysis}

Data were analyzed with the IBM SPSS software version 27 (IBM Corp., New York, USA). Continuous variables were presented as means and standard deviations, or as medians and interquartile ranges (IQR). Reduction rates were calculated as one minus the fracture risk ratio. We compared changes in fracture rates between five age groups: infants and toddlers $(0-<3$ years $)$, pre-school children $(3-<7$ years $)$, school children $(7-<11$ years $)$, early adolescence $(11-<15$ years $)$, and late adolescence (15- $<18$ years). Means were compared using the $T$-test for independent samples; fracture rates and proportions were compared using the chi-square test. Ninety-five percent confidence intervals (CI) were calculated for all analyses. Two-tailed analyses were done for all tests. The probability level $<0.05$ was considered significant.

\section{Ethical considerations}

This study was reviewed and approved by the Institutional Review Board of Meuhedet Health Services (number 01-10-06-20). 
Table 1 Summary of previous studies of pediatric orthopedic trauma during the COVID-19 pandemic

\begin{tabular}{|c|c|c|c|c|}
\hline Study [ref] & Setting & Study period & Control period & Main findings \\
\hline Peiro-Garcia et al., Spain [5] & Single center & 14.3.2020-14.4.2020 & $\begin{array}{l}\text { Same period in the previous } \\
2 \text { years }\end{array}$ & $\begin{array}{l}\text { The number of orthopedic } \\
\text { patients admitted to the ER } \\
\text { dropped by } 78 \% \text { during the } \\
\text { study period }\end{array}$ \\
\hline Memeoe et al., Italy [6] & Single center & 23.2.2020-15.4.2020 & $\begin{array}{l}\text { Same period in the previous } \\
\text { year }\end{array}$ & $\begin{array}{l}\text { A reduction of } 78 \% \text { pediatric } \\
\text { visits in trauma ER but an } \\
\text { increase of } 22 \% \text { in pediatric } \\
\text { fractures }\end{array}$ \\
\hline Bolzinger et al., France [7] & Single center & 17.3.2020-10.5.2020 & $\begin{array}{l}\text { Same period in the previous } \\
3 \text { years }\end{array}$ & $\begin{array}{l}\text { During lockdown, pediatric } \\
\text { traumatology emergency } \\
\text { activity decreased by } 50 \% \text {. } \\
\text { The number of patients } \\
\text { operated was } 86 \% \text { of that in } \\
\text { the previous } 3 \text { years }\end{array}$ \\
\hline Raittio et al., Finland [8] & 5 tertiary centers & 1.3.2020-31.5.2020 & $\begin{array}{l}\text { Same period in the previous } \\
4 \text { years }\end{array}$ & $\begin{array}{l}\text { Trauma operations decreased } \\
\text { significantly ( } 31 \%, \\
p=0.03 \text { ). Daycare, school, } \\
\text { and organized sports- } \\
\text { related injuries decreased } \\
\text { significantly }\end{array}$ \\
\hline Baxter et al., UK [9] & $\begin{array}{l}\text { A pediatric major trauma } \\
\text { center and } 4 \text { district general } \\
\text { hospitals }\end{array}$ & 24.3.2020-10.5.2020 & $\begin{array}{l}\text { Same period in the previous } \\
\text { year }\end{array}$ & $\begin{array}{l}\text { Pediatric trauma admissions } \\
\text { across the region fell by } \\
33 \% \text { (132 vs. } 197)\end{array}$ \\
\hline Keays et al., Canada [10] & Single center & 16.3.2020-15.5.2020 & Same period over 28 years & $\begin{array}{l}\text { Decreased fracture rates } \\
\text { were significant for all age } \\
\text { groups. Compared with the } \\
\text { 2015-2019 average, the } \\
\text { decrease was smaller in the } \\
\text { 0-5 year age group (a 33\% } \\
\text { decrease) and greater in the } \\
\text { 6-17 year age group ( } 70 \% \text { ) }\end{array}$ \\
\hline Nabian et al., Iran [11] & Single center & $1.3 .2020-15.4 .2020$ & $\begin{array}{l}\text { Same period in the previous } \\
2 \text { years }\end{array}$ & $\begin{array}{l}\text { The number of pediatric } \\
\text { trauma admissions dropped } \\
\text { from } 589 \text { to } 288 \text {, and of } \\
\text { fractures from } 295 \text { to } 145\end{array}$ \\
\hline Bram et al., USA [12] & Single center & 15.3.2020-15.4.2020 & $\begin{array}{l}\text { Same period in the previous } \\
2 \text { years }\end{array}$ & $\begin{array}{l}\text { The incidence of frac- } \\
\text { tures decreased during } \\
\text { the pandemic (from } \\
22.5 \pm 9.1 \text { to } 9.6 \pm 5.1 \\
\text { per day, } p<0.001 \text { ). The } \\
\text { presenting age for fractures } \\
\text { decreased (from } 7.5 \pm 4.3 \text { to } \\
9.4 \pm 4.4 \text { years, } p<0.001 \text { ) } \\
\text { because of decreased } \\
\text { fracture burden among } \\
\text { adolescents }\end{array}$ \\
\hline
\end{tabular}

ER emergency room

\section{Results}

\section{Fracture rates}

During 2020, 10,701 fractures occurred. This compared with a mean of $12,574 \pm 599$ fractures per year in the five previous years (the control period) ( $p$-value $<0.001)$. The proportion of fractures that occurred in boys in 2020 was similar to the proportion in the control period $(64.8 \%$ vs. $64.4 \%, p$-value $=0.37)$.

Fracture rates were lower during all periods in 2020 than in the reference periods in 2015-2019 (Table 2; Fig. 1). The greatest decline was recorded during the first lockdown (period 2) for both boys (56\% decline, CI 52-60\%) and girls (47\% decline CI 41-53\%). During period 3 , which followed the first lockdown, the trend 
Table 2 Fracture rates in children ${ }^{1}$ per 10,000 person-years, during 2020 compared with 2015-2019

\begin{tabular}{|c|c|c|c|c|c|c|c|c|}
\hline & \multicolumn{4}{|l|}{ Boys } & \multicolumn{4}{|l|}{ Girls } \\
\hline & $2015-2019$ & 2020 & $\%$ reduction & $95 \% \mathrm{CI}$ of reduction & 2015-2019 & 2020 & $\%$ reduction & $95 \% \mathrm{CI}$ of reduction \\
\hline Period 1 & 297 & 284 & $4 \%$ & $-1 \%-10 \%$ & 168 & 154 & $8 \%$ & $1-15 \%$ \\
\hline Period 2 & 340 & 148 & $56 \%$ & $52 \%-60 \%$ & 193 & 102 & $47 \%$ & $41-53 \%$ \\
\hline Period 3 & 337 & 306 & $9 \%$ & $5 \%-16 \%$ & 204 & 169 & $17 \%$ & $12-21 \%$ \\
\hline Period 4 & 332 & 241 & $28 \%$ & $20 \%-34 \%$ & 201 & 150 & $26 \%$ & $16-34 \%$ \\
\hline Period 5 & 335 & 302 & $10 \%$ & $5 \%-15 \%$ & 187 & 179 & $4 \%$ & $-3-11 \%$ \\
\hline
\end{tabular}

Period 1 - from 1.1.20 until 13.3.20, before the first lockdown

Period 2 - from 14.3.20 until 2.5.20, the first lockdown

Period 3 - from 3.5.20 until 17.9.20, schools were open partially and intermittently

Period 4 - from 18.9.20 until 16.10.20, the second lockdown

Period 5 - from 17.10 .20 until 27.12.20, schools were open partially and intermittently

$\mathrm{CI}$ - confidence interval

${ }^{1}$ Children insured by Meuhedet Health Services in Israel

partially reversed for boys, and to a lesser extent for girls, the respective reductions were 9\% (CI 5-16\%) and 17\% (CI 12-21\%). During the second lockdown (period 4), the rates dropped again for both sexes, though less dramatically than during the first lockdown (reduction of $28 \%$, CI $20-34 \%$ for boys and $26 \%$, CI $16-34 \%$ for girls). The reversal in trend was partial for boys and full for girls in the following and last period (reduction of $10 \%$, CI 5-15\% for boys and $4 \%, \mathrm{CI}-3-11 \%$ for girls).

\section{Age at fracture}

For boys, the median age at fracture was 11 years (IQR 6-12) during 2020, and 11 years (IQR 7-13) during 2015-2019. For girls, the median age at fracture was 9 years (IQR 4-11) during 2020 and 9 years (IQR 5-12) during 2015-2019.

During the first lockdown, the fracture rate declined for age groups: 3-6, 7-10,11-14, and 15-17 years (Fig. 2). The largest decline was recorded for age group 11-14 years, with a significant reduction rate of $66 \%$ (CI 59-71\%) for boys and $65 \%$ (CI 54-73\%) for girls. The fracture rate did not change significantly for the $0-2$ year age group.

\section{Fracture site}

Table 3 presents fracture rates during 2020 and the reference period, 2015-2019, by fracture site. The most common fracture site for boys and girls was the radius/ulna, followed by the carpal/metacarpal/phalanges, for 2020 , as well as for the reference period. The reduction in fracture rates was greatest for fractures of the carpal/metacarpal/phalanges for both boys and girls (64\% (CI 56-70\%) and 58\% (CI 45-67\%), respectively). The declines in fractures of the femur in boys and in fractures of the femur, tibia/fibula, and trunk in girls were not statistically significant.

\section{Discussion}

To the best of our knowledge, this is the first pediatric study to evaluate the impact of COVID-19 on pediatric fractures during the entire year of 2020 compared with the previous 5 years (2015-2019). We further analyzed five periods within 2020, two of which were lockdown periods during the first and second waves of the COVID-19 pandemic in Israel. This study demonstrates declines in fracture rates during lockdown periods, with only partial reversing of the trends between and following the lockdown periods. Our data suggest that even between lockdown periods, children did not return to their regular daily activities.

The COVID-19 pandemic has impacted many aspects of daily life of children and adolescents, specifically with the closing of schools and playgrounds and the decrease in organized sports. Consequent to these public health measures, changes in incidences and patterns of pediatric fractures occurred. Compared to the previous 5 years, fracture rates were lower during all periods in 2020 . The most pronounced decline was during the first lockdown: a $56 \%$ decline in fracture rate in boys and a $47 \%$ decline in girls. Similar decreases in pediatric traumatic injuries and fractures were reported in other countries during that period [10-12]. Only one study from Italy did not show a decrease in the incidence of pediatric fractures, despite a decrease of $78 \%$ in pediatric trauma visits in the emergency room. A meta-analysis of 16 studies that included a total of 11,963 patients (mainly adults) found that the number of fractures declined by $43 \%(35-50 \%)$ compared to pre-pandemic incidence [13].

In the current study, the decrease in fracture rate during the second lockdown was less prominent than during the first lockdown, probably because the restrictions in the second lockdown were less severe. Between the lockdown periods, we found partial reversal in the trend of decreased incidence 
Fig. 1 The monthly variation in fracture rates per 10,000 patient-years in 2020 compared with the average rates in 2015-2019
Boys

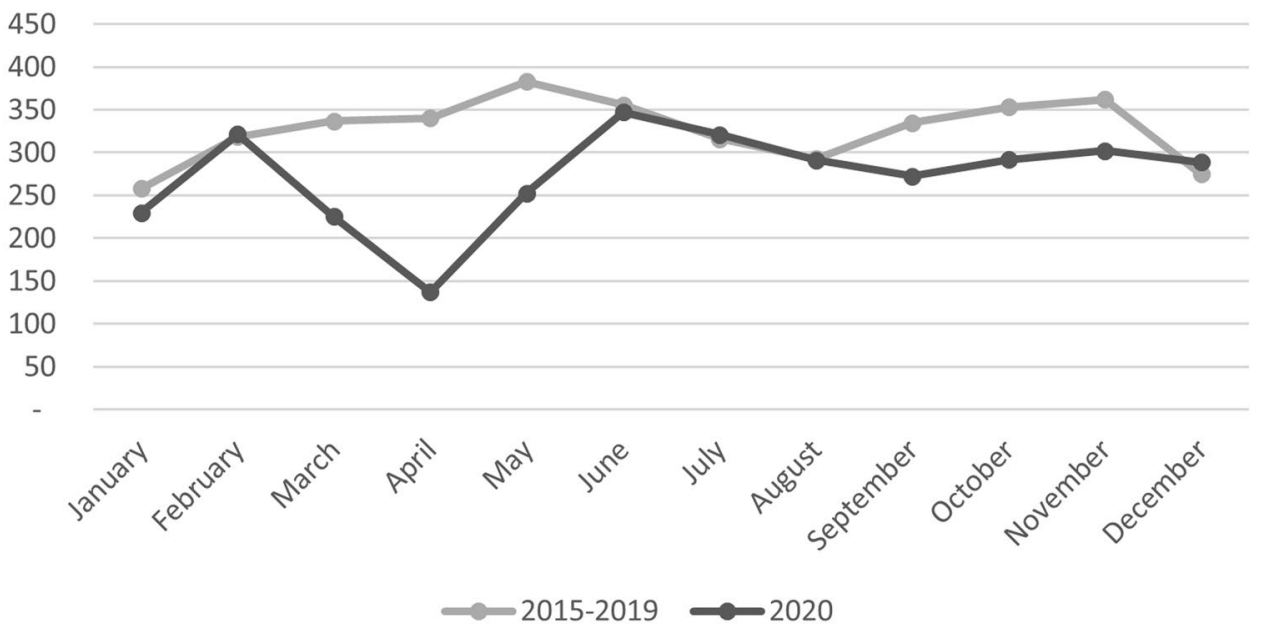

Girls

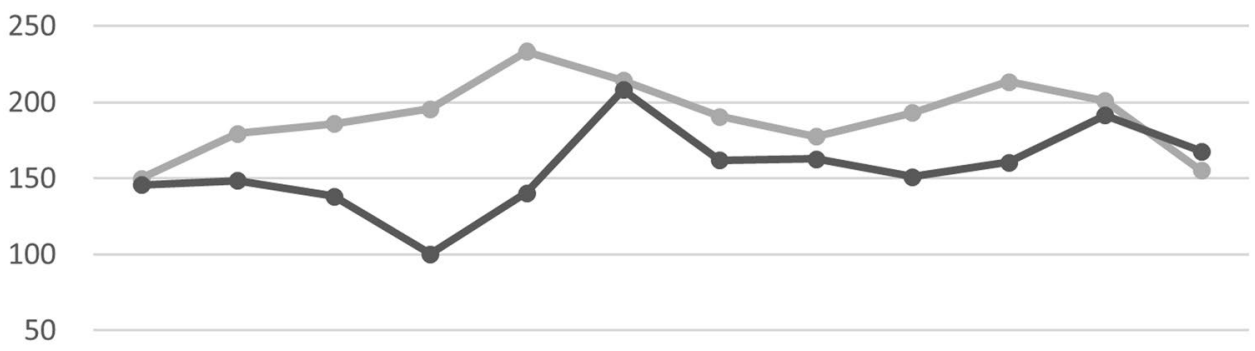

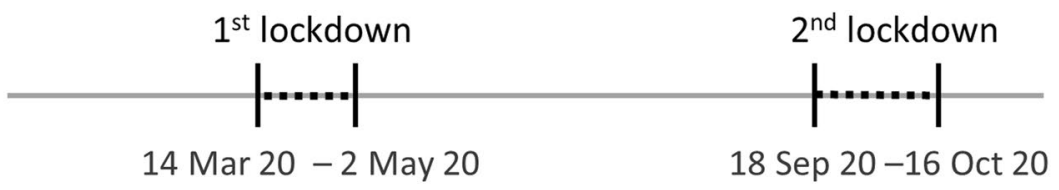

of fractures. Two studies that evaluated the impact of COVID19 on orthopedic and trauma numbers in trauma centers also found a partial U-shaped reversal in the trend after the lockdown [14, 15]. Since pediatric fractures are considered an indicator of children's regular daily physical activity [4], our data may indicate that during 2020, Israeli children did not return to their regular activities, even when restrictions were removed. Indeed, a study that evaluated physical activity of Dutch children during 2020 found that reopening schools and organized sports after the lockdown did not result in restored physical activity levels in children [16]. This point should be studied further to quantify the future impact of lockdowns and the pandemic on public health.
The sex ratio of about $60 \%$ boys and $40 \%$ girls with new fractures did not change during 2020, as was also reported for the lockdown period in Toulouse, France [7]. This ratio concurs with previous studies [17, 18, 20].

We demonstrated that the decline in fracture rate was most prominent in adolescents aged 11-14 years $(66 \%$ decline in boys and $65 \%$ decline in girls) and least prominent in children under age 3 years. This finding corroborates data during the COVID-19 pandemic in the USA and Canada [10, 12]. The explanation for the prominent decrease in adolescents is probably cancellations of sports activities. Notably, the relation between physical activity and fracture risk has two sides. On one hand, controlled, weight-bearing physical 
A

Boys

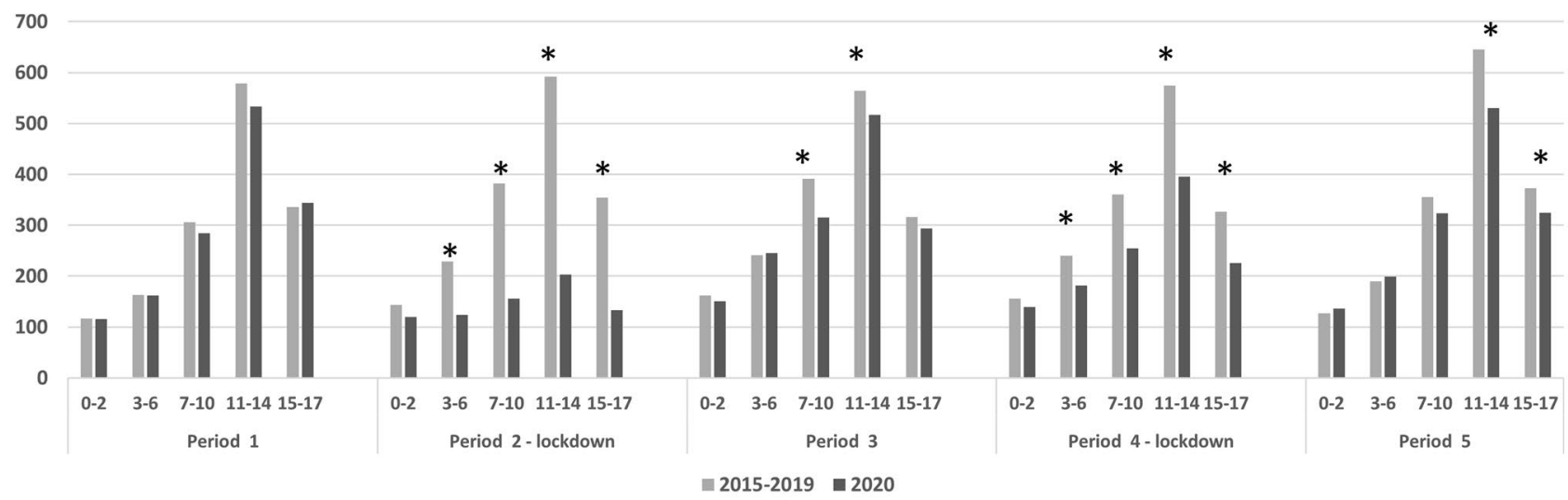

B Girls

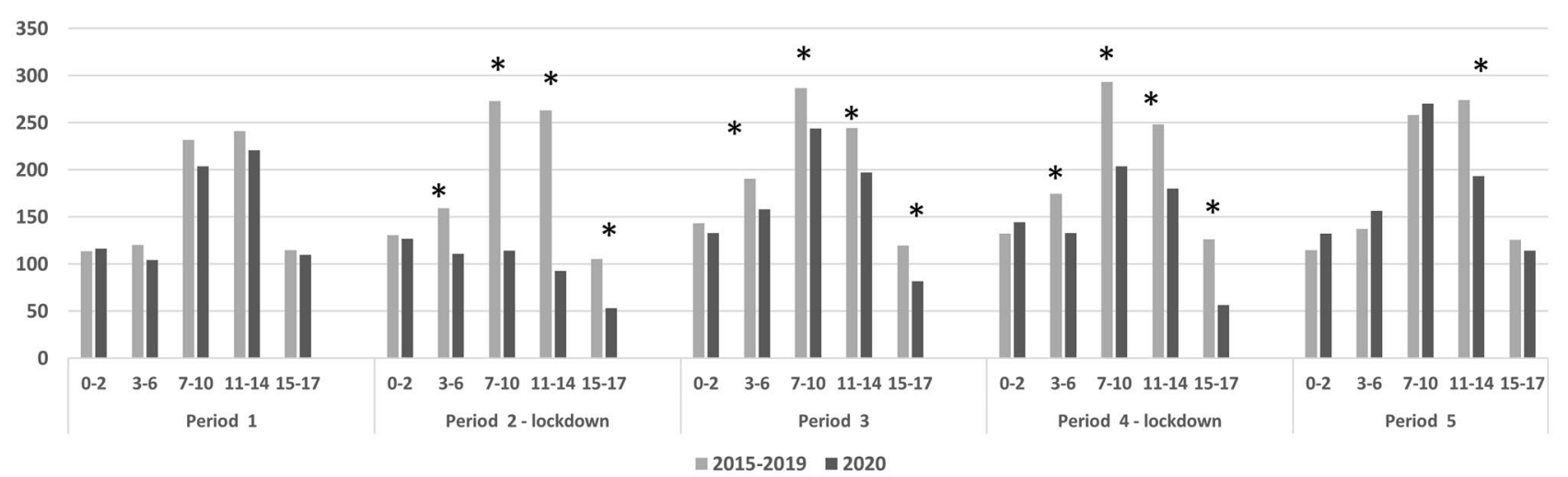

Fig. 2 Incidence fracture rates per 10,000 patient-years for the various age groups during the periods evaluated $(*) p$-value $<0.05$

Table 3 Reductions in fracture rates in children ${ }^{1}$, according to site, during 2020 compared with 2015-2019

\begin{tabular}{lllllc}
\hline & Fracture site & $\mathbf{2 0 1 5 - 2 0 1 9}$ & $\mathbf{2 0 2 0}$ & Reduction & 95\% CI \\
\hline Boys & Carpal/metacarpal/phalanges* & 91 & 33 & $64 \%$ & $56-70$ \\
& Radius/ulna* & 108 & 47 & $56 \%$ & $49-63$ \\
& Humerus* & 22 & 10 & $53 \%$ & $33-66$ \\
& Tarsal/metatarsal/phalanges* & 32 & 17 & $47 \%$ & $31-59$ \\
& Tibia/fibula* & 27 & 16 & $40 \%$ & $21-54$ \\
& Femur & 4 & 2 & $47 \%$ & $-9-75$ \\
& Face/skull* & 15 & 6 & $59 \%$ & $36-74$ \\
Girls & 12 & 6 & $51 \%$ & $22-69$ \\
& Trunk* & 45 & 19 & $58 \%$ & $45-67$ \\
& Carpal/metacarpal/phalanges* & 45 & $45 \%$ & $32-55$ \\
& Radius/ulna* & 56 & 31 & $46 \%$ & $20-63$ \\
& Humerus* & 16 & 9 & $54 \%$ & $34-68$ \\
& Tarsal/metatarsal/phalanges* & 21 & 10 & $17 \%$ & $-10-38$ \\
Tibia/fibula & 20 & 16 & $-36-78$ \\
Femur & 3 & 2 & $46 \%$ & $17-79$ \\
Face/skull* & 6 & 3 & $58 \%$ & $-56-32$ \\
\hline Trunk & 8 & 8 & $-3 \%$ &
\end{tabular}

Fracture rates per site per 10,000 person-years

CI $-95 \%$ confidence interval

$*$ p-value $<0.05$

${ }^{1}$ Children insured by Meuhedet Health Services in Israel 
activity in children improves bone density and size, and reduces fracture risk [21]. On the other hand, vigorous activity is related to fall accidents and increased risk of fractures in the short term $[19,21]$. We do not have data on the mechanism of fractures, but other studies demonstrated decreases in sports-related injuries during the COVID-19 period [13, 14]. This is consistent with reductions in fractures in the short term. It will be interesting to evaluate longer term bone health following the COVID-19 restrictions.

Our data show significant reductions in fracture rates of almost all fracture sites. The declines in fracture of the femur in boys and in fractures of the femur, tibia/fibula, and trunk in girls were not statistically significant, probably due to the low numbers of fractures in those sites.

The main strengths of our study are its large nationwide cohort and the long time period included in the study, which enabled analysis of distinct periods during the COVID-19 pandemic. The data of 2020 were compared to a control period of 5 years, eliminating the influence of variations between years. Still, some limitations should be acknowledged. We relied on the accuracy of the diagnosis of fractures coded by physicians in a non-experimental setting, and information about the mechanisms of the fractures was unavailable.

In conclusion, this epidemiological study described the incidence of fractures in children in Israel during a full year of the COVID-19 pandemic. We showed a significant decrease in fracture rate compared to the previous 5 years, and also differences between periods within that year. This epidemiological information may help healthcare planning and appropriate allocation of medical services in future similar situations. Moreover, our data suggest that during the entire year of 2020, children did not return to their regular activities. This aspect of the pandemic and lockdowns may affect children's future physical wellbeing and mental health. Policy makers and health organizations should be aware of this possible impact and address it.

Author's contributions GZ and YLS contributed to the conception and design of the study, acquisition of data, analysis, interpretation of data, and drafting the article. DMM and LTS contributed to interpretation of the data and revised the manuscript critically for important intellectual content. All the authors gave their final approval of the submitted version.

Availability of data and material The collected data for this study are available from the corresponding author on reasonable request.

\section{Declarations}

Ethics approval The study was approved by the Institutional Review Board of Meuhedet Health Services (number 01-10-06-20).

Consent to precipitate Not applicable.

Consent to publication Not applicable.
Conflict of interest The authors declare no competing interests.

\section{References}

1. Mahase E (2020) Covid-19: WHO declares pandemic because of alarming levels of spread, severity, and inaction. BMJ 368:m1036. https://doi.org/10.1136/bmj.m1036

2. Cooper C, Dennison EM, Leufkens HG, Bishop N, van Staa TP (2004) Epidemiology of childhood fractures in Britain: a study using the general practice research database. J Bone Miner Res 19(12):1976-1981. https://doi.org/10.1359/JBMR.040902

3. Zacay G, Dubnov-Raz G, Modan-Moses D, Tripto-Shkolnik L, Levy-Shraga Y (2021) Epidemiology of childhood fractures in Israel during 2000-2019. Bone 154:116174. Epub 12 Sept 2021. https://doi.org/10.1016/j.bone.2021.116174.

4. Mathison DJ, Agrawal D (2010) An update on the epidemiology of pediatric fractures. Pediatr Emerg Care 26(8):594-603. https:// doi.org/10.1097/PEC.0b013e3181eb838d

5. Peiro-Garcia A, Corominas L, Coelho A, DeSena-DeCabo L, Torner-Rubies F, Fontecha CG (2020) How the COVID-19 pandemic is affecting paediatric orthopaedics practice: a preliminary report. J Child Orthop 14(3):154-160. https://doi.org/10.1302/ 1863-2548.14.200099

6. Memeo A, Priano D, Caldarini C, Trezza P, Laquidara M, Montanari L et al (2020) How the pandemic spread of COVID-19 affected children's traumatology in Italy: changes of numbers, anatomical locations, and severity. Minerva Pediatr Epub 6 Oct 2020. https://doi.org/ 10.23736/S0026-4946.20.05910-1.

7. Bolzinger M, Lopin G, Accadbled F, Sales de Gauzy J, Compagnon R (2021) Pediatric traumatology in green zone during Covid-19 lockdown: a single-center study. Orthop Traumatol Surg Res 102946. Epub 27 Apr 2021. https://doi.org/10.1016/j.otsr.2021.102946.

8. Raitio A, Ahonen M, Jaaskela M, Jalkanen J, Luoto TT, Haara $M$ et al (2020) Reduced number of pediatric orthopedic trauma requiring operative treatment during COVID-19 restrictions: a nationwide cohort study. Scand J Surg 1457496920968014. Epub 27 Oct 2020. https://doi.org/10.1177/1457496920968014.

9. Baxter I, Hancock G, Clark M, Hampton M, Fishlock A, Widnall $\mathrm{J}$ et al (2020) Paediatric orthopaedics in lockdown: a study on the effect of the SARS-Cov-2 pandemic on acute paediatric orthopaedics and trauma. Bone Jt Open 1(7):424-430. https://doi.org/10. 1302/2633-1462.17

10. Keays G, Friedman D, Gagnon I (2020) Injuries in the time of COVID-19. Health Promot Chronic Dis Prev Can 40(11-12):336341. https://doi.org/10.24095/hpcdp.40.11/12.02

11. Nabian MH, Vosoughi F, Najafi F, Khabiri SS, Nafisi M, Veisi J et al (2020) Epidemiological pattern of pediatric trauma in COVID19 outbreak: data from a tertiary trauma center in Iran. Injury 51(12):2811-2815. https://doi.org/10.1016/j.injury.2020.09.015

12. Bram JT, Johnson MA, Magee LC, Mehta NN, Fazal FZ, Baldwin KD et al (2020) Where have all the fractures gone? The epidemiology of pediatric fractures during the COVID-19 pandemic. J Pediatr Orthop 40(8):373-379. https://doi.org/10.1097/BPO. 0000000000001600

13. Lim MA, Mulyadi Ridia KG, Pranata R (2021) Epidemiological pattern of orthopaedic fracture during the COVID-19 pandemic: a systematic review and meta-analysis. J Clin Orthop Trauma 16:16-23. https://doi.org/10.1016/j.jcot.2020.12.028

14. Maleitzke T, Pumberger M, Gerlach UA, Herrmann C, Slagman A, Henriksen LS et al (2021) Impact of the COVID-19 shutdown on orthopedic trauma numbers and patterns in an academic Level I Trauma Center in Berlin, Germany. PLoS One 16(2):e0246956. https://doi.org/10.1371/journal.pone.0246956 
15. Vaishya R, Vaish A, Kumar A (2021) Impact of COVID-19 on the practice of orthopaedics and trauma-an epidemiological study of the full pandemic year of a tertiary care centre of New Delhi. Int Orthop Epub 4 Oct 2021. https://doi.org/10.1007/ s00264-021-05021-5.

16. Ten Velde G, Lubrecht J, Arayess L, van Loo C, Hesselink M, Reijnders D et al (2021) Physical activity behaviour and screen time in Dutch children during the COVID-19 pandemic: pre-, during- and post-school closures. Pediatr Obes 16(9):e12779. Epub 23 Feb 2021. https://doi.org/10.1111/ijpo.12779.

17. Joeris A, Lutz N, Wicki B, Slongo T, Audige L (2014) An epidemiological evaluation of pediatric long bone fractures - a retrospective cohort study of 2716 patients from two Swiss tertiary pediatric hospitals. BMC Pediatr 14:314. https://doi.org/10.1186/ s12887-014-0314-3

18. Naranje SM, Erali RA, Warner WC, Jr. Sawyer JR, Kelly DM (2016) Epidemiology of pediatric fractures presenting to emergency departments in the united states. J Pediatr Orthop 36(4)e45-8. https://doi.org/10.1097/BPO.0000000000000595.

19. Randsborg PH, Gulbrandsen P, Saltyte Benth J, Sivertsen EA, Hammer OL, Fuglesang HF, et al (2013) Fractures in children: epidemiology and activity-specific fracture rates. J Bone Joint Surg Am 95(7):e42. https://doi.org/10.2106/JBJS.L.00369

20. Fritz J, Coster ME, Nilsson JA, Rosengren BE, Dencker M, Karlsson MK (2016) The associations of physical activity with fracture risk-a 7-year prospective controlled intervention study in 3534 children. Osteoporos Int 27(3):915-922. https://doi.org/ 10.1007/s00198-015-3311-y

21. Hedstrom EM, Svensson O, Bergstrom U, Michno P (2010) Epidemiology of fractures in children and adolescents. Acta Orthop 81(1):148-153. https://doi.org/10.3109/17453671003628780

Publisher's Note Springer Nature remains neutral with regard to jurisdictional claims in published maps and institutional affiliations. 